\title{
Exploring the potential for crowdsourced spatial information to inform debate related to the changing Canadian local news landscape
}

JON CORBETT

Community Culture and Global Studies University of British Columbia Okanagan jon.corbett@ubc.ca

\author{
APRIL LINDGREN \\ School of Journalism \\ Ryerson University \\ april.lindgren@ryerson.ca
}

\section{ABSTRACT}

This paper investigates an applied participatory mapping research project that enables members of the public to crowdsource information for Canada's first community spatial database documenting contemporary changes to local news outlets. This data is presented on the Local News Map, which locates where news organizations are closing or cutting back services and where new outlets are launched or services are increased. The tool, released in mid-2016 by Canadian academics, is a web-based, interactive platform that displays map markers and descriptive information about changes to local television, radio, online sites and newspapers dating from 2008 to the present. Map filters allow users to select and view specific information about these changes. We explore the impact of the project, demonstrating that the map has enriched the public sphere by generating robust empirical data on news outlets that have shut down or launched or increased/decreased service in their communities. Specifically, we found strong and ongoing demand from journalists who use the platform's data to provide context for stories about the ongoing disruption in the local news sector. We also identify other impact indicators for further investigation.

\section{Introduction}

Citizens, politicians and academics are following the decline and disappearance of local news in Canada with growing concern. Local journalism in this country and elsewhere faces what researchers have described as an "uncertain future" (Nielsen, 2015, p. 2). U.S. researchers, for instance, have documented the rise of local news deserts (Napoli, Weber, McCollough \& Wang, 2018) and the emergence of "ghost newspapers" where the few surviving reporters at a publication can no longer adequately cover news in their communities (Abernathy, 2018, p. 28).

The debate over how to respond to the local news "crisis" (Gasher et al., 2016) in Canada has been impeded by inadequate data related to what is happening to news outlets at the local level, as well as the number and location of affected communities. Politicians, (Canada, Parliament, House of Commons, 2017), think tanks (Public Policy Forum, 2017) and scholars (Ali, 2016) have all called for better data to inform the discussion.

This article contributes to the growing interest in 'impact' as it relates to participatory mapping practice and research. Specifically, we discuss the extent to which the Local News Map, displaying data from Canada's first crowdsourced community spatial database, has informed the public debate about the state and future 
of local journalism in the country. The platform itself captures and displays changes to local news organizations by tracking broadcast, online and print outlets that have closed or cut back services, as well

\section{Background}

The use of digital mapping and spatial data visualization to investigate locally important issues is a growing area of interest in both the discipline of geography and cartography. Historically, cartographic theory focused on how best to characterize spatial data using static representations of space (Kitchin, Perkins \& Dodge, 2009). The postrepresentational approach of more recent cartographic theorists looks beyond what maps represent and instead explores their "effects on the world" (Kitchin, Dodge and Perkins 2011, 6). Viewed in these terms, digital web-based maps in particular are evolving interactive practices that offer engaging data visualization tools and act as knowledge generators. Furthermore, they hold the potential "to illuminate, uncover, and provoke insights and new connections" (Allen \& Queen, 2015, p. 91) and can be used to "solve diverse and context-dependent problems" (Kitchin \& Dodge, 2007, 342). Integral to this perspective is the notion that contemporary digital maps, rather than being fixed artifacts, are dynamic and display an unfolding narrative.

The multi-disciplinary practice of participatory mapping intentionally sets out to address social issues (Corbett \& Cochrane, 2017). The Local News Map provides a good example of this because it explicitly aims to support the creation of a citizen-curated spatial database that addresses the pressing need for up-to-date data on a rapidly evolving issue of national concern.

In this article, we investigate the impact of the Local News Map by evaluating its contributions to the public sphere, that is, the extent to which it is informing public discussion about the condition of local journalism. German sociologist Jurgen as the launch of new outlets or expansion of existing services. The changes are presented using location markers on a digital interactive

map.

Habermas conceived of the public sphere as a place where the news media provided discursive space for debating and deliberating important matters: "If, as democratic theory holds, democracy requires a well-informed and engaged citizenry, then the media must provide the resources - news, information and opinion for a self-governing people to identify and work towards matters of common concern" (Howley, 2007, 343). At the same time, Kovach and Rosenstiel argue in their seminal text The Elements of Journalism, that for journalism to be a public forum it must rest on a foundation of fact and context. In the absence of that foundation, they observe "the debate will cease to educate, it will only reinforce the preconceptions people arrive wwith, and the public will be less able to participate in solutions" (2014, 210).

The map is a joint project of academics at the University of British Columbia and Ryerson University. Analysis of its impact is timely in that many participatory mapping projects, particularly those based in universities, fail to sufficiently articulate outcomes because "systematic measurements and indicators [of the] impact on the social, cultural, political, and organizational dimensions are almost totally absent" (Godin \& Dore, 2004). There is, nonetheless, a growing interest in the study of impact, especially from funding agencies and post-secondary institutions. Within the field of participatory mapping, there are also tensions that arise between different understandings of "impact." Impact can be understood from an academic perspective, i.e. which projects have yielded the most journal article citations. Impact can also be understood from the viewpoint of the community of practice, i.e. which projects resulted in substantive and sustained social or political transformation. There are 
further ambiguities that arise and interact with these tensions; ambiguities around how impact is understood within academic articles, policy documents, and reports to funding agencies, and whether the practice of participatory mapping truly influences change for the institutions, communities, or individuals involved.

\section{The Local New Map}

The Local News Map, launched online in June 2016, was created to address the need for a comprehensive dataset documenting changes to local news outlets across Canada (Lindgren, Corbett \& Hodson, 2017). It captures and displays crowdsourced data on a digital interactive map. The information covers the time period from 2008 to present. We chose 2008 as the starting point because it marked the beginning of 'The Great Recession' and the collapse of advertising revenue that devastated many once-profitable local news outlets (Canadian Media Concentration Research Project, 2017).

Registered users can add information to the map through a simple wizard-driven interface. Registration is managed by a moderator who also verifies that the information submitted by the user is accurate. Each marker displays information about changes to a local media outlet including:

- the closing, launch or merger of a news outlet;

- service increases such a greater publication frequency for a community paper;

- service reductions such as a broadcaster's decision to cancel/reduce the duration of a local newscast;

- mergers of local news outlets that result in the launch of a new entity and/or the closing of an existing news operation.

Users click on a map marker to view a popup window containing the name of the media outlet, a short description of the change that occurred, the date of the change and the owner of the news operation. For verification purposes, the pop-up also includes links to stories, press releases and other informational sources related to that specific event. Filters allow users to sort the markers by news outlet ownership, by media type and by the nature of change (whether it is a new local media outlet or one that has closed or an operation that has merged or increased or decreased service).

As of October 1, 2018, when we last analyzed the platform's data, there were 471 markers on the map representing changes to local broadcast, newspaper and online news outlets over the past decade. This included 260 news outlets of all types that have closed in 190 different places. Community newspapers (published fewer than five times per week) have been the hardest hit - 189 have shut down since 2008. In contrast, only 93 new local news operations have launched in 69 different communities (Lindgren and Corbett, 2018).

\section{Methods}

To answer our research question "Has the Local News Map enriched the public sphere by informing public discussion about development in local journalism?" we examined how frequently the map and its associated data are mentioned and cited in news reports. The original Habermasian public sphere concept was criticized for failing to acknowledge that public discourse was dominated by white affluent men criticism that "underscores the problem of conceptualizing the public sphere as a single, inclusive and comprehensive discursive space" (Howley, 2007, 345). We therefore also explore the range of media sources that make use of the data in their reporting - to what extent are they providing different publics with access to verified data and information about the state of local news in Canada?

The list of media references to the Local News Map was assembled by combining the authors' list of map-related interviews, 
opinion columns, and data requests from journalists with the results of web searches. We conducted the searches using various combinations of the key words "Local News Map," "journalism," "Canada," "closing" "newspapers" and "newsroom" and the names of the map's authors.

\section{Results: The map in the news}

A total of 78 references to the Local News Map or its data appeared in news stories during the 29 months between June 2016 and November 2018. In cases where the same story appeared in multiple media outlets, we counted each story because the target audience was different in every case.

A flurry of stories appeared when the map initially launched, including, for instance, an article on a popular website that focuses on Canadian journalism news. This article discussed the map's goals, how it worked and the data it had generated up to that point in time (Ghosh, 2016). Longer features subsequently cited the number of newly launched local news outlets and the number of news outlets that have closed. Map data have been requested and used to provide context in longer features about the prospects of individual news outlets, including a Walrus magazine story that ran under the headline "Inside the Toronto Star's bold plan to save itself" (Popplewell, 2018). The data have also been used in indepth stories about the future of local journalism overall. For example, the Toronto Star story "Journalists are vanishing. Who will fill the void?" explored the challenges faced by local news, the role of local journalism in communities and possible solutions (Wallace, 2017).

Demand for the data spiked when journalists sought to make sense of significant developments within the news industry. Seventeen of the 78 references to map data, for instance, occurred in late November 2017 when the PostMedia and TorStar chains announced they were exchanging multiple newspapers and then closing three dozen publications (Krashinksy Robertson, 2017). News stories about the closings cited the Local News Map data to provide context for what is happening to local journalism in general (Healing, 2017). Longer features, meanwhile, discussed the state of the newspaper industry in individual communities (Miller, 2017).

There is also evidence suggesting the map has had an impact on conversations about local journalism in different public spheres, albeit some more so than others. Its reach beyond mainstream English-language media was limited. Rabble.ca was the only instance where an alternative news outlet referenced the Local News Map and only two French-language media outlets made use of its data. That said, the map data did reach a variety of publics. While the majority (10) of national news organizations that referenced the map served the private sector, its content was made available to the audiences of two public broadcasters - the CBC and Ontario's TVO. It was at the local and regional level, however, where the map and its data contributed most significantly to distinct conversations: Local media serving nearly two dozen communities from Victoria, B.C. and Whitehorse in the Yukon to London, Ont., and St. John's, N. B. carried broadcast interviews or news stories - many of them generated locally, some of them provided by wire services - that referenced its data. During a series of CBC radio interviews in different Ontario communities in mid-October 2018, for instance, local hosts requested map data for the province and explored how the loss of so many community newspapers might affect coverage of municipal elections that were underway. At a regional level, the closing of several newspapers in Saskatchewan in late 2017 led to a provincial call-in show on CBC radio about the state of local news media and similar requests for province-specific data on newsroom losses. 


\section{Conclusion}

The speed and scale of recent changes to Canadian local media has been profound. Understanding the nature of the disruption, meanwhile, is about more than just curiosity: Local news media play a critical role in supplying what researchers have identified as eight critical information needs of communities - a list that includes information about risks and emergencies, health, education, transportation, economic opportunities, the environment and civic and political information (Friedland, Napoli, Ognyaova, Weil and Wilson, 2012).

Our research question asked about the Local News Map's impact on the public sphere and we found that it has indeed enriched both national and local conversations by supplying up-to-date data on changes to local news ecosystems. The incorporation of map data into media stories that are widely circulated to different publics is, however, only one measure of the map's impact. The next step in evaluating the impact of this example of scholarly praxis will be to evaluate the map as a tool for knowledge generation and its impact on the policymaking process.

\section{Acknowledgements}

This paper was written with financial support from the SSHRC-funded Geothink Project. The authors would also like to thank Nick Blackwell, the computer programmer for the Local News Map and Local News Research Project research assistant Christina Wong.

\section{References}

Abernathy, P. (2018). The Expanding News Desert. Centre for Innovation and Sustainability in Local Media. University of North Carolina at Chapel Hill. Retrieved from http://www.usnewsdeserts.com/repor ts/expanding-news-desert/downloada-pdf-of-the-report/
Ali, C. (2016). Understanding Canadian local news ecosystems: An international comparative approach. pp 125-145 in Eds. Gasher, Mike, Colette Brin, Christina Crowther, Gretchen King, Errol Salamon and Simon Thibault. 2016 Journalism in Crisis: Bridging Theory and Practice for Democratic Media Strategies in Canada. Toronto: University of Toronto Press.

Allen, T. \& Queen, S. (2015). Beyond the map: Unpacking critical cartography in the digital humanities. Visible Language: The Journal of Visual Communication Research, 49(3), 7998.

Canada, Parliament, House of Commons Standing Committee on Canadian Heritage. (2017). Disruption: Change and churning in Canada's media landscape. Retrieved from http://www.ourcommons.ca/Content /Committee/421/CHPC/Reports/RP9 045583/chpcrpo6/chpcrpo6-e.pdf

Canadian Media Concentration Research Project. (2017). The Growth of the Network Media Economy in Canada, 1984-2016. Retrieved from http://www.cmcrp.org/wpcontent/uploads/2017/11/Growth_of _the_Network_Media_Economy_No vember_2017.pdf

Corbett, J. M., \& Cochrane, L. (2017). Engaging With the Participatory Geoweb: Experiential Learning From Practice. In Volunteered Geographic Information and the Future of Geospatial Data (pp. 1-18). IGI Global.

Friedland, Lewis, Napoli, Philip, Ognyaova, Katherine, Weil, Carola \& Wilson III, Earnest J. (2012). Review of the literature regarding the critical information needs of the American public. Retrieved from https://transition.fcc.gov/bureaus/oc bo/Final Literature Review.pdf 
Gasher, M., Colette B., Crowther, C., King, G., Salamon E. and Thibault S. (Eds). (2016). Journalism in Crisis: Bridging Theory and Practice for Democratic Media Strategies in Canada. Toronto: University of Toronto Press.

Ghosh, I. (June 14, 2016). Crowd-sourced map tracks what's happening to local news outlets across Canada. Retrieved from: http://www.jsource.ca/article/crowd-sourcedmap-tracks-what\%E2\%80\%99shappening-local-news-outlets-acrosscanada

Godin, B., \& Doré, C. (2004). Measuring the impacts of science: Beyond the economic dimension. History and sociology of S\&T statistics.

Healing, D. (Nov. 27, 2017). Torstar, Postmedia newspaper closures aim to cut competition: analysts. Retrieved from:

https://www.vicnews.com/business/t orstar-postmedia

Howley, K. (2007). Community Media and the Public Sphere. In (Ed). Eoin Devereux. Media Studies: Key Issues and Debates. London: Sage Publications.

Kitchin, R., Dodge, M. \& Perkins, C. (2011). Introductory Essay: Conceptualizing Mapping. In Martin Dodge, Rob Kitchin and Chris Perkins (Eds.), The Map Reader: Theories of Mapping practice and Cartographic Representations (pp. 2-7). New York: John Wiley and Sons.

Kitchin, R. \& Dodge, M. (2007). Rethinking Maps. Progress in Human Geography. Vol. 31(3), 331-344.

Kitchin, R., Perkins, C. \& Dodge, M. (2009). Thinking about Maps. In Dodge, Kitchin and Perkins (Eds.), Rethinking Maps (pp. 1-25). New York: Routledge.
Kovach, B. \& Rosenstiel, T. (2014). The Elements of Journalism: What Newspeople Should Know and the Public Should Expect. New York: Three Rivers Press.

Krashinksy Robertson, S. (Nov. 27, 2017). Postmedia, Torstar to swap and shutter dozens of local newspapers. https://www.theglobeandmail.com/re port-on-business/torstar-postmediaswap-community-papers-many-toclose/article37092456/

Lindgren, A., Corbett, J. \& and Jaigris Hodson. "Canada's Local News "Poverty." Policy Options. Accessed January 23, 2017. http://policyoptions.irpp.org/magazin es/january-2017/canadas-local-newspoverty/.

Lindgren, A. \& Corbett, J. Local News Map Data, Oct. 1, 2018. Retrieved from: http://localnewsresearchproject.ca/w pcontent/uploads/2018/10/LocalNews MapDataasofOctober12018.pdf

Miller, J. (July 27, 2017). Local news is disappearing in Ontario, and that's bad for democracy. TVOntario. Retrieved from: https://tvo.org/article/currentaffairs/the-next-ontario/-local-newsis-disappearing-in-ontario-and-thatsbad-for-democracy

Napoli, Philip M., Weber, Matthew, McCollough, Katie \& Wang, Qun. (2018) Assessing Local Journalism: News Deserts, Journalism Divides, and the Determinants of the Robustness of Local

News. https://dewitt.sanford.duke.ed u/wpcontent/uploads/2018/o8/AssessingLocal-Journalism 100Communities.pdf

Nielsen, R. K. (2015). Introduction: The uncertain future of local journalism. 
In Nielsen, R.K .(Ed). Local Journalism: The Decline of Newspapers and the Rise of Digital Media. London: I.B. Tauris \& Co. pp 125.

Popplewell, Brett. (May 10, 2018). Inside the Toronto Star's Bold Plan to save itself. The Walrus. Retrieved from: https://thewalrus.ca/inside-thetoronto-stars-bold-plan-to-save-itself/

Public Policy Forum. (2017). Shattered mirror: News, democracy and trust in the digital age. Retrieved from: https://shatteredmirror.ca/downloadreport/

Wallace, C. (Feb. 4, 2017). Journalists are vanishing: Who will fill the void? Toronto Star. https://www.thestar.com/news/atkin sonseries/newnewsroom/2017/journa lists-are-vanishing-who-will-fill-thevoid.html 